\title{
The role of South African researchers in intercontinental collaboration
}

\author{
Csaba Kozma $^{1} \cdot$ Clara Calero-Medina $^{1}$ (D)
}

Received: 5 December 2018 / Published online: 23 September 2019

(c) The Author(s) 2019

\begin{abstract}
The analysis presented here focuses on mapping, based on publication output, the scientific collaboration of African based researchers and the role of the South African research community as a channel for within- and intercontinental collaborations. We have selected 10 scientific fields, namely, Tropical Medicine, Parasitology, Infectious Disease, Ecology, Water Resources, Immunology, Zoology, Plant Sciences, Agricultural and Food Sciences, and Psychology to gain a clear picture of the aforementioned scientific activity. As a first step, we created cooperation networks and visualized them on world-maps. In addition, centrality measures of the network were calculated to see the frequency of involvement regarding different countries, with a focus on South Africa, in the collaboration process. Furthermore, first and last authorship positions of the publications were summed to highlight the influence of the selected authors on the direction of and resources provided to the publications. Finally, the most prominent funding organizations and their focus on the selected fields were singled out. Through combining these steps of analysis, we gained an accurate picture of the level of involvement of the South African research community in within- and intercontinental scientific collaboration.
\end{abstract}

Keywords Scientific collaboration · Research communities · South Africa · Intercontinental $\cdot$ Co-authorship $\cdot$ VosViewer

\section{Introduction}

In recent decades, scientific collaboration has been a significant part of emerging research communities as, by $2016,60 \%$ of the total scientific publications were internationally coauthored (UNESCO 2010; NSB 2016). The relationships between organizations, authors, and/or governing bodies can be manifested in multiple ways. Even though collaborative research increasingly gains value among researchers across the world, the evaluation of

Clara Calero-Medina

clara@cwts.leidenuniv.nl

Csaba Kozma

csaba.a.kozma@gmail.com

1 Centre for Science and Technology Studies (CWTS), Leiden University, P.O. Box 905, 2300 AX Leiden, The Netherlands 
these relations is still poorly understood (Klein 2008; Yegros-Yegros et al. 2015). Discussions about the quality and quantity of intra- and internationally collaborative research have taken place over a diversity of forums, and consequently, it will be essential to facilitate broader integration of the research evaluating and investigating this collaborative research (Klein 2008; Mâsse et al. 2008; Yegros-Yegros et al. 2015).

The analysis presented here focuses on mapping, based on publication output, the scientific collaborating activity of African authors, with a specific focus on studying the role of the South African research community as a channel for intercontinental collaborations. The analysis of the publications will be focused on: scientific fields to determine differences or similarities among them, authorship positions to determine the leadership on the research, and funding analysis to determine the financial leadership of the research. The research questions that triggers this study is to what extend African researchers are integrated in the international collaboration network and what is the specific role of South African researchers.

\section{Literature review}

In order to analyse scientific collaboration, some theoretical principles has already been considered. Starting with the variability of goals, the process of integration or transcendence of single fields can be viewed as an epistemological investment to produce a wider and more accurate pool of knowledge on the investigated phenomenon (Klein 2008). This endeavour is based on the collection and reformation of theoretical attributes, procedures, and skills (Sonnenwald 2007). The collaboration occurs at the level of researchers while institutions take a secondary but vital role of supporting the realisation of the connection between the authors (Sooryamoorthy 2013b). In addition, there is a high emphasis on methodological interdisciplinarity as it provides the integrating medium that can capitalize on the different theoretical approaches (Mâsse et al. 2008; Sonnenwald 2007). However, it is crucial to consider that contribution from researchers is measured via variability of criteria and indicators based on field specific metrics that are unlikely to be compatible across different scientific areas. Besides the field specific differences, it is crucial to highlight that the relative contribution to each field has been distorted by certain geographic biases. Sooryamoorthy and Shrum (2007) found that in South Africa, in particular, the introduction of Internet technology curtailed the hindrances that fuel geographic biases and deny the possibility of international cooperation. Furthermore, the involved funding organizations have been specifically tailored to research topics that accommodate western researchers and research practices (Mâsse et al. 2008). This is a clear after effect of the extended influence of colonialism that limited the resources and directions according to western interests on the African continent (Beaudry and Mouton 2017). Due to this bias, prominent funding organizations focus on western research interests, which are not necessarily in alignment with the African continent`s R\&D priorities (Beaudry and Mouton 2017).

With the above in mind, we need to be careful in how to evaluate the indicators of collaborative research in the current scientific world (Hicks et al. 2015). Furthermore, effective leverage on integration is important. It is necessary to focus on not just on outcomes, but also on the processes of integrative research by, for example, providing transparent descriptions of everyone's capabilities and background knowledge, so that the emerging project can maximize the effectiveness of the collaboration (Sonnenwald 2007; OECD 2016; Sooryamoorthy 2013b). In addition, recognizing the importance of social and cognitive 
aspects of collaboration can smooth out the process of interaction between cooperating researchers (Mâsse et al. 2008; Sonnenwald 2007). The continuous and systematic interaction of collaborators and subgroups of the project diminish the possibility of failure of the project (Klein 2008; Evans et al. 2011). It is important to engage in clear and effective management and coaching of the common project (Sonnenwald 2007). To make this happen, the members need to introduce common boundary objects, integrated decision-making platforms, and consensus building processes (Klein 2008). Finally, scientific collaboration needs to be built on transparent feedback systems between researchers both inside and outside of the immediate network of collaborators. The dynamic evaluation of each-other's work, the relative contributions of collaborators, and the overarching progress of the project need to be clearly interpretable by all the involved parties (Roper 2002; Sooryamoorthy and Shrum 2007).

\section{Specific issues regarding international collaboration within Africa}

It is important to clarify if and how collaborative research can circumvent emerging power imbalances in African scientific contributions that have been introduced and reinforced by colonialism (Briggs and Weathers 2016). As Nhemachena et al. (2016) argues: "African culture since the colonial era originated from methodological practices that took Africa as a "field" without organic cultivators. Such [a] conceptualization of Africa merely as a field for mining "raw data" has legitimized centuries-old (neo-) colonial epistemic and methodological experiments on the people of the continent." (See pp. 15). This detrimental epistemological approach to African scientific contributions necessitates the rigorous and critical evaluation of the current intercontinental influence on African research collaborations. This current paper aims to reflect on the potential steps that the international scientific community needs to take in order to organically involve the highly valuable and impactful contribution that comes out of the African continent.

Regarding collaboration among African researchers, African researchers tend to collaborate within their own countries than within their own organization. Least frequently, they tend to cooperate with researchers from other African countries (Beaudry and Mouton 2017). In the case of South Africa, research institutes contribute most often to within-country collaborations while universities predominantly contribute to international collaborations (Sooryamoorthy 2013a).

In terms of intercontinental collaboration with the African continent, some authors show that it is very important for the future of African research to establish a balanced partnership with researchers and institutions located in Africa and ensure that the quantity and quality of involvement is equally discussed and agreed upon (Dodsworth and Cheeseman 2017).

In parallel to the described cooperative trends, it is important to note that international cooperation is frequently present in the case of publications that are produced by authors with the highest scientific impact (AOSTI 2014). According to the African Observatory of Science, Technology and Innovation (AOSTI), the top 500 most cited African researchers 'have more than $50 \%$ of their publications co-authored, primarily with researchers outside Africa’ (AOSTI 2014: 38). 


\section{International and domestic funding}

Finally, it is necessary to mention the impact of the source and nature of funding that supports each publication within these collaborations. The evaluation of the involvement of international and domestic funding organizations is relevant to determine the potential goals and challenges of each publication (Beaudry and Mouton 2017; OECD 2016). The influence of these institutions, in addition to providing funds for the publication, mainly affects the continuity of research programs in African countries (Beaudry and Mouton 2017). They function as donors for $\mathrm{R} \& \mathrm{D}$ projects, or work as the integrating body for international and/or intercontinental collaboration (Sonnenwald 2007; OECD 2016). In addition, they are potential providers of employment for local scientists and providers of facilities and technology that are, currently, not accessible in the countries receiving the funding (Beaudry and Mouton 2017).

The aforementioned attributes of integrative scientific research collaboration are fundamental; each research community has its own features that potentially vary based on the involved fields, geographic location, underlying organizations, institutes, and funding (Evans et al. 2011; Sonnenwald 2007).

\section{Methods}

Our approach is based on a quantitative analysis of scientific publications in journals processed in the Web of Science (WoS) versions of the Science Citation Index and associated citation indices. These are the Science Citation Index (SCI), the Social Science Citation Index (SSCI), and the Arts \& Humanities Citation Index (A\&HCI). The Centre for Science and Technology Studies (CWTS) database contains these records. The publication proceedings database within the WoS database is not included in this study. Below, we present the different steps followed for the selection of the dataset and the analysis.

\section{Selected scientific fields}

As a first step, we selected 10 scientific fields that are largely influential regarding the number of publications originating from African countries as well as contributing significantly to the global output in those fields (Beaudry and Mouton 2017). They serve as indicators to map the scientific cooperation involving the African continent and identifying South Africa as a beacon in this process. These fields consist of Tropical Medicine, Parasitology, Infectious Disease, Ecology, Water Resources, Immunology, Zoology, Plant Sciences, Psychology, and Agricultural and Food Sciences. Psychology was selected to gain insight into the impact of a scientific field that is radically different from the rest of the fields that all fall under the category of physical sciences. Furthermore, partnerships among African researchers and development organizations have a long tradition in technical fields, as well as fields that are tied to the continent's geopolitical situation and natural resources (Beaudry and Mouton 2017).

\section{Selection of authors}

Within these fields, we have selected authors that published between 2000 and 2017. In addition, we have created three groups based on the registered location of the affiliated institution of the authors. The first group included authors who have published mainly 
under an address of a South African institution. The next group included authors who have published mainly under an address in any African country other than South Africa, which gives a continental overview of the publication frequency in the field. Finally, the last group consisted of authors who have published mainly under an address outside of Africa. Additionally, we have filtered out authors who have published either the same or more publications than the mean quantity of publications within the respective field (see Table 1). Even though the Standard Deviation (SD) of the distribution of publications tends to be quite high (see Table 1), we have used the mean value as a cut off limit as it has been established as a standard (size independent) indicator of individual productivity (Ruiz-Castillo and Costas 2014).

After the accommodation of the prior mentioned filters, we listed the amount of publications and journals that served as data for our analysis (see Table 2).

\section{Co-authorship maps}

Based on the data, we have created co-authorship matrices between the selected researchers, which we visualized via co-authorship maps in VosViewer 1.6.6 (Van Eck and Waltman 2010; Ranjbar-Sahraei and Negenborn 2017) (see Fig. 1a in "Results" section and Figs. 2, 3, 4, 5, 6, 7, 8, 9, 10a).

\section{Locate the most influential sub-community in each field}

In order to find out which sub-communities had the highest influence on specific field in terms of cooperation, we calculated the centrality measures in the cooperation networks. We have selected the three most frequently used centrality indicators, namely, betweenness, degree, and closeness (Wasserman and Faust 2016). These measurements highlight the position and connectedness of the particular researcher. The converted network files from VosViewer were transferred to Pajek64 5.03 (Batagelj and Mrvar 2003) to calculate the centrality measurements. To implicate the pattern of presence in within- and intercontinental collaboration, we selected out the 10 most influential researchers who have the highest scores in each of the centrality measurements, listed their belonging countries, focusing on the African countries. This was important in order to gain a picture about the distribution of research collaboration in the selected fields on the continent (Table 3 in "Results" section and Tables 7, 8, 9, 10, 11, 12, 13, 14, 15 in "Appendix"). Furthermore, we have conducted a Louvain Modularity analysis, using Pajek, on each of the networks that depict the collaboration between African and non-African researchers in each field. This was done to identify the exact sub communities that collaborate frequently. This method is based on the density of connecting edges and compares the inside to the outside of the selected community in the network (see Figs. 1, 2, 3b) (Blondel et al. 2008). We selected this tool of modularity since it is both intuitive and easy to generate compatible text files that can be fed into VosViewer.

\section{Authorship position}

Furthermore, we have looked at the number of authors for each publication and have conducted an analysis of their authorship position. We have counted the number of authors whose affiliated addresses are most often located in South Africa and take first and/or last 
Table 1 Quantity of authors; mean, standard error (SE) and standard deviation (SD) of publications for each author, within the selected fields, within South Africa (ZA), rest of African continent (AF) and nonAfrican countries (NA)

\begin{tabular}{|c|c|c|c|c|}
\hline Field & Quantity of authors & Mean & SE & SD \\
\hline Psychology (ZA) & 581 & 14 & 0.668 & 40,903 \\
\hline Psychology (AF) & 463 & 25 & 1.248 & 45,032 \\
\hline Psychology (NA) & 125,981 & 14 & 0.057 & 49,896 \\
\hline Agricultural and Food Sciences (ZA) & 1440 & 20 & 0.646 & 47,819 \\
\hline Agricultural and Food Sciences (AF) & 3092 & 15 & 0.248 & 27,635 \\
\hline Agricultural and Food Sciences (NA) & 249,158 & 15 & 0.049 & 49,448 \\
\hline Zoology (ZA) & 287 & 53 & 1.353 & 73,968 \\
\hline Zoology (AF) & 634 & 39 & 1.057 & 72,787 \\
\hline Zoology (NA) & 35,254 & 48 & 0.214 & 100,538 \\
\hline Water Resources (ZA) & 401 & 26 & 0.987 & 46,299 \\
\hline Water Resources (AF) & 1384 & 19 & 0.600 & 46,341 \\
\hline Water Resources (NA) & 30,708 & 36 & 0.220 & 92,845 \\
\hline Tropical Medicine (ZA) & 229 & 63 & 2.465 & 84,817 \\
\hline Tropical Medicine (AF) & 747 & 63 & 0.812 & 102,833 \\
\hline Tropical Medicine (NA) & 15,933 & 59 & 0.178 & 102,833 \\
\hline Plant Sciences (ZA) & 164 & 90 & 3.835 & 290,842 \\
\hline Plant Sciences (AF) & 760 & 47 & 2.067 & 228,257 \\
\hline Plant Sciences (NA) & 43,285 & 45 & 0.153 & 106,264 \\
\hline Parasitology (ZA) & 182 & 61 & 2.085 & 70,802 \\
\hline Parasitology (AF) & 1076 & 38 & 0.955 & 91,013 \\
\hline Parasitology (NA) & 19,468 & 61 & 0.424 & 148,497 \\
\hline Infectious Diseases (ZA) & 1074 & 20 & 0.990 & 110,475 \\
\hline Infectious Diseases (AF) & 3724 & 20 & 0.521 & 100,578 \\
\hline Infectious Diseases (NA) & 76,351 & 40 & 0.225 & 178,504 \\
\hline Immunology (ZA) & 181 & 107 & 1.410 & 95,387 \\
\hline Immunology (AF) & 1836 & 39 & 0.723 & 104,783 \\
\hline Immunology (NA) & 99,741 & 68 & 0.218 & 211,941 \\
\hline Ecology (ZA) & 433 & 49 & 1.455 & 105,083 \\
\hline Ecology (AF) & 932 & 39 & 1.105 & 97,326 \\
\hline Ecology (NA) & 34,093 & 50 & 0.158 & 89,591 \\
\hline
\end{tabular}

authorship positions in publications in the selected fields. This step allows for a more accurate picture of the role of the South African research community in the scientific collaborative process while also clarifying the influence and presence of these researchers in each field and publication. Typically, the first author position indicates the most influence and effort given to the writing of the publication, while the last position is frequently assigned to the senior author, typically independent of the level and amount of contribution given by that author (Bhattacharya 2010). Between these two positions, the line of authors is typically defined by the relative contribution to the writing process (Bhattacharya 2010). In addition, the authorship position allows us to have better insight about the actual impact and effort given by the selected authors on the publications. This relation also helps 
Table 2 The number of publications and journals in the selected scientific fields in South Africa (ZA), rest of African continent (AF) and non-African countries (NA)

\begin{tabular}{|c|c|c|}
\hline Field & $\begin{array}{l}\text { Number of } \\
\text { publications }\end{array}$ & $\begin{array}{l}\text { Number } \\
\text { of jour- } \\
\text { nals }\end{array}$ \\
\hline Psychology (ZA) & 3416 & 363 \\
\hline Psychology (AF) & 659 & 131 \\
\hline Psychology (NA) & 492,549 & 630 \\
\hline Agricultural and Food Sciences (ZA) & 6722 & 355 \\
\hline Agricultural and Food Sciences (AF) & 11,856 & 397 \\
\hline Agricultural and Food Sciences (NA) & 691,827 & 497 \\
\hline Zoology (ZA) & 2306 & 122 \\
\hline Zoology (AF) & 3461 & 141 \\
\hline Zoology (NA) & 134,219 & 185 \\
\hline Water Resources (ZA) & 1556 & 61 \\
\hline Water Resources (AF) & 4084 & 80 \\
\hline Water Resources (NA) & 104,282 & 101 \\
\hline Tropical Medicine (ZA) & 767 & 16 \\
\hline Tropical Medicine (AF) & 5951 & 21 \\
\hline Tropical Medicine (NA) & 56,648 & 25 \\
\hline Plant Sciences (ZA) & 4153 & 158 \\
\hline Plant Sciences (AF) & 8043 & 193 \\
\hline Plant Sciences (NA) & 250,855 & 231 \\
\hline Parasitology (ZA) & 845 & 30 \\
\hline Parasitology (AF) & 4898 & 35 \\
\hline Parasitology (NA) & 55,850 & 39 \\
\hline Infectious Diseases (ZA) & 5084 & 74 \\
\hline Infectious Diseases (AF) & 14,791 & 85 \\
\hline Infectious Diseases (NA) & 201,082 & 91 \\
\hline Immunology (ZA) & 2876 & 110 \\
\hline Immunology (AF) & 9685 & 152 \\
\hline Immunology (NA) & 418,740 & 175 \\
\hline Ecology (ZA) & 3745 & 128 \\
\hline Ecology (AF) & 5359 & 133 \\
\hline Ecology (NA) & 175,216 & 166 \\
\hline
\end{tabular}

exploring the reasons for the selection of preferred topics by the major funding organizations involved in supporting the publications selected for our analysis (see next paragraph; Table 5 in "Results" section).

\section{Funding organizations of South African publications}

Based on the data we have selected, we identified the 10 most frequently involved funding organizations which are supporting publications that have at least one author whose affiliated addresses are most often located in South Africa (see Table 6 in "Results" section). In Table 5, we included the primary scientific field that each funding organization has contributed towards within South Africa. 
(A)

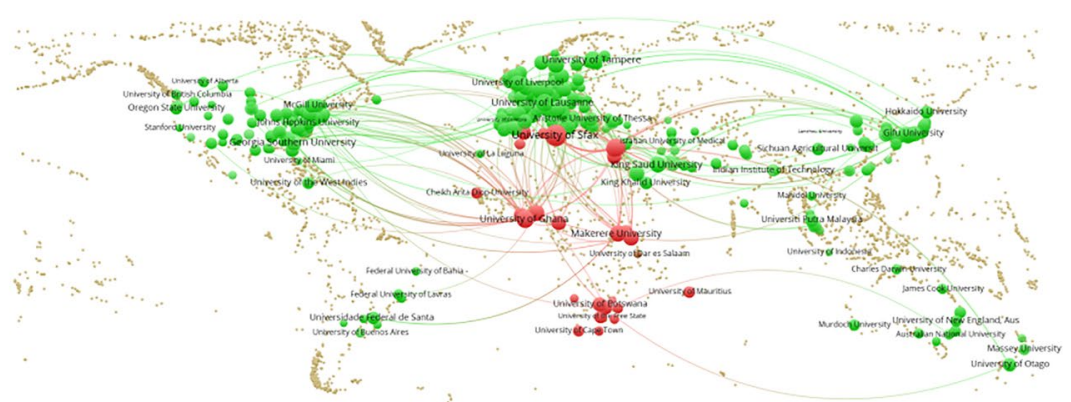

A vosviewer

(B)

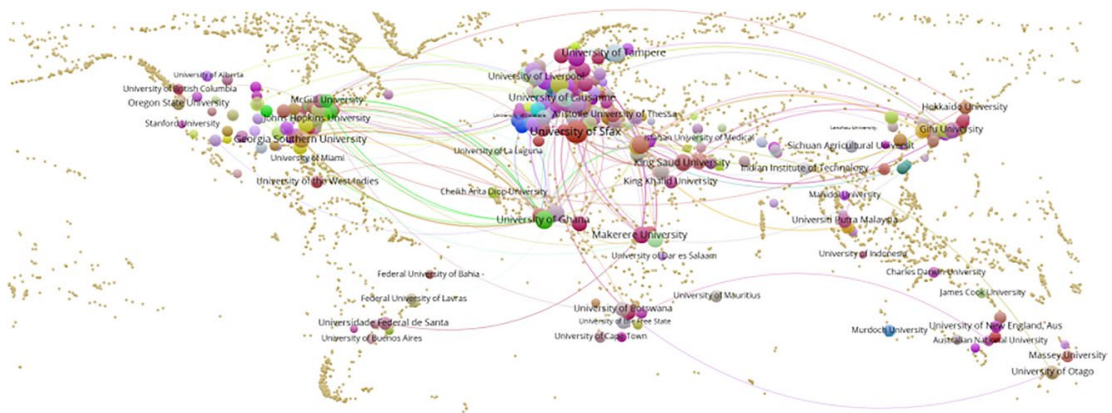

As vosviewer

Fig. 1 a Collaboration between African and non-African research institutes in the field of Agricultural and Food Sciences. Red nodes represent African institutions and green nodes represent non-African institutions. b Collaboration split to communities between African and non-African research institutes in the field of Agricultural and Food Sciences (Louvain Modularity). Each colour represents different communities based on the density of edges (representing collaboration) connecting the institutions. (Color figure online)

In addition, we selected the top 10 most involved funding organizations, per field, from around the world, that are providing financial support for publications in which at least one author, with a South African address or alternative address, is contributing. The identification of the involvement of funding organizations creates the possibility to gain clarity about underlying perspectives and motives of the scientific collaborative projects that turn into publications. We have done this analysis for each of the 10 fields (see Table 6 in "Results" section; see Tables 16, 17, 18, 19, 20, 21, 22, 23, 24 in “Appendix").

\section{Results}

\section{Most influential African researchers in the cooperation network}

The analysis show that based on the calculated centrality measures, South African collaborative presence, dominates in Zoology, Ecology, Water Resources, and Plant Sciences 
Table 3 Agricultural and Food Sciences centrality measurements

\begin{tabular}{lllllll}
\hline \multicolumn{2}{l}{ Agricultural and Food Sciences } & & & & \\
\hline Position & Betweenness & Countries & Closeness & Countries & Degree & Countries \\
\hline 1 & 0.009641 & ZA & 0.026263 & ZA & 39 & ZA \\
2 & 0.009276 & EG & 0.025799 & NG & 36 & NG \\
3 & 0.007508 & CA & 0.025748 & ZA & 24 & ZA \\
4 & 0.007113 & KN & 0.025447 & GH & 24 & GH \\
5 & 0.007087 & GH & 0.025165 & KN & 21 & KN \\
6 & 0.006671 & NG & 0.024774 & KN & 20 & KN \\
7 & 0.006612 & TU & 0.024584 & EG & 18 & EG \\
8 & 0.005674 & EG & 0.024406 & CA & 18 & CA \\
9 & 0.005658 & EG & 0.02435 & UG & 16 & UG \\
10 & 0.005066 & ZA & 0.023623 & EG & 14 & EG \\
\hline
\end{tabular}

(see Tables $7,8,9,10,11,12,13,14,15$ ). This means that the most central collaborating author is affiliated to a South African institution for four of the 10 identified fields. However, the centrality measures also depict the amount of co-publications that are present between authors located on the African continent, for our purpose the most important result is their relative position on the lists (see Table 3; see Tables 7, 8, 9, 10, 11, 12, 13, 14, 15 in "Appendix"). These positions work as indicator for their cooperative influence in the sub-community, based on the field and geographical location. Overall, these results are a clear depiction of the role of South African research communities as prominent beacons for intercontinental scientific collaboration in at least four different major scientific fields based on our results.

Furthermore, the generated collaboration maps show the amount of intercontinental cooperation for each selected field as well as the identified hubs on the African continent: Fig. 1a (see Figs. 2, 3, 4, 5, 6, 7, 8, 9, 10a in "Appendix"). These hubs further indicate the involvement of the South African research community in between- and within continent cooperation in the aforementioned four fields (Zoology, Ecology, Water Resources, and Plant Sciences). In order to select the most influential intercontinental cooperative communities, we have created maps based on the Louvain Modularity scores that were assigned to each node in the underlying cooperation networks (see Fig. 1b; see Figs. 2, 3, 4, 5, 6, 7, 8, 9, 10b in "Appendix"). The nodes and the corresponding tags represent the institutions that the publications are affiliated with (based on the CWTS database).

Figure 1a (and Figs. 2, 3, 4, 5, 6, 7, 8, 9, 10a in "Appendix") show that South African collaborative contributions are particularly dominant in the 4 aforementioned mentioned fields (see Figs. 3a, 4a, 6a, 10a in "Appendix"), an effect, which was also depicted by the centrality measures described above. Regarding the rest of the fields, we see a more scattered involvement of different authors from different countries throughout Africa, especially in Infectious Diseases, Tropical Medicine, Psychology, and Agricultural and Food Sciences. Regarding the field of Psychology, we see that a trend towards collaborating with non-Asian countries is apparent (see Fig. 2a).

It is important to clarify that the depiction on the figures can be dependent on either the high number of authors per publication or the high number of publications in the field. The two possibilities have different qualitative value in the perspective of collaboration. This difference in the diversity of structure in communities of collaboration between fields 
can be supported by multitude of reasons, for example specific institutional interests, geopolitical underpinnings, or global scientific projects, which are outside of the scope of this paper.

Finally, it is necessary to point out that the colouring on Fig. 1b (and Figs. 2, 3, 4, 5, 6, $7,8,9,10 \mathrm{~b}$ in "Appendix") highlights that the specific communities include majorly intercontinental cooperation, that also involve African presence, with field specific geographical biases that are also visible on Fig. 1a (and Figs. 2, 3, 4, 5, 6, 7, 8, 9, 10a in "Appendix"). These biases include, among others, European and Northern-American dominance and a higher frequency involvement of Asian institutions in biomedical related sciences (such as the field of Tropical Medicine). Outside of the field of Tropical Medicine, South Africa's presence is clearly observed and is distinguished with respect to establishing frequent international collaborations on the African Continent.

\section{Authorship position}

In order to identify the direct impact of the selected authors on the particular publications, we have counted the amount of papers where these researchers were named as first and/or last authors. Note that for this analysis, we have only included scientific publications where at least two authors were listed (see Table 4).

The highest proportion of first authors is in the field of Psychology, followed by Agricultural and Food Sciences, Water Resources, Zoology and Ecology (see Table 4). These fields show a first authorship rate of over $15 \%$ of the total number of publications (equal or more than 2 authors per publication), while the rest of the selected fields span between 10 and 14\%. Concerning the last author position, most are found in the Plant Sciences, followed by Zoology, Water Resources, and Ecology (see Table 4). The results show that, other than in the field of Psychology, first author position for authors that have registered addresses and/or alternative address in South Africa is always below $20 \%$ of the total amount of publications. These results highlight the fact that even though the total amount of cooperation involving authors with addresses registered in an African country is highest in the fields of Ecology and Zoology; this does not mean that they are the first authors of those publications. The combination of the cooperation maps with the authorship position draws a more accurate picture about the impact of the selected fields and the level of influence of authors located in South Africa.

\section{Overall and field based funding profiles (ZA)}

We have found that, regarding the involvement of funding organizations, the majority tend to prioritize Astronomy and Astrophysics as well as Particle and Field Physics (see Table 5). This could be explained by several causes. First, it is the presence of supporting institutions, mainly with focus of funding priorities coming out of European and NorthernAmerican countries, and apparatuses, such as Southern African Large Telescope (SALT), that give a significant advantage to South Africa in these fields (Whitelock and Oluseyi 2008). Second, the current evolution and trend in technological inventions and modifications, specifically, recent inventions in quantum technology, allow for the testing of the underlying theoretical concepts that have been around in the last few decades (O'Brien 2017; Preskill 2018). In addition, the necessarily high amount of investment in these technologically demanding fields presupposes the deployment of more global and financially extensive investment policies (Gibney 2016). Furthermore, these fields are considered 
Table 4 Authorship position of authors whose primary or alternative address is located in South Africa for the selected fields based on publications between 2000 and 2017

\begin{tabular}{|c|c|c|}
\hline Field (total number of publications with $2+$ authors) & Position & $\begin{array}{l}\text { Proportion taken by the } \\
\text { position from total (\%) }\end{array}$ \\
\hline \multirow[t]{2}{*}{ Zoology (2878) } & First & 17.90 \\
\hline & Last & 43.12 \\
\hline \multirow[t]{2}{*}{ Water Resources (2114) } & First & 18.73 \\
\hline & Last & 37.51 \\
\hline \multirow[t]{2}{*}{ Plant Sciences (5635) } & First & 11.55 \\
\hline & Last & 45.66 \\
\hline \multirow[t]{2}{*}{ Tropical Medicine (1099) } & First & 12.28 \\
\hline & Last & 29.84 \\
\hline \multirow[t]{2}{*}{ Parasitology (1138) } & First & 12.30 \\
\hline & Last & 30.76 \\
\hline \multirow[t]{2}{*}{ Infectious Diseases (12286) } & First & 13.73 \\
\hline & Last & 20.90 \\
\hline \multirow[t]{2}{*}{ Immunology (4514) } & First & 10.63 \\
\hline & Last & 27.78 \\
\hline \multirow[t]{2}{*}{ Ecology (5083) } & First & 16. 07 \\
\hline & Last & 37.18 \\
\hline \multirow[t]{2}{*}{ Agricultural and Food Sciences (10477) } & First & 19.33 \\
\hline & Last & 32.15 \\
\hline \multirow[t]{2}{*}{ Psychology (3982) } & First & 24.08 \\
\hline & Last & 33.93 \\
\hline
\end{tabular}

Table 5 Top 10 most involved funding organizations for publications in which at least one author, whose primary or alternative address is located in South Africa, is contributing (scientific field focus)

\begin{tabular}{llll}
\hline Place & Funding organization & $\begin{array}{l}\text { Number of } \\
\text { funded publica- } \\
\text { tions }\end{array}$ & Field \\
\hline 1 & National Aeronautics and Space Administration & 779 & Astronomy and astrophysics \\
2 & National Research Foundation of South Africa & 773 & Astronomy and astrophysics \\
3 & Science and Technology Facilities Council & 770 & Astronomy and astrophysics \\
4 & National Research Foundation of South Africa & 753 & Plant sciences \\
5 & National Research Foundation of South Africa & 679 & Ecology \\
6 & National Research Foundation of South Africa & 671 & Physics, particles and fields \\
7 & Science and Technology Facilities Council & 668 & Physics, particles and fields \\
8 & National Natural Science Foundation of China & 649 & Physics, particles and fields \\
9 & Conselho Nacional de Desenvolvimento Científico e & 636 & Physics, particles and fields \\
10 & Tecnológico-CNPq & & National Institute of Allergy and Infectious Diseases \\
\hline
\end{tabular}

mega-sciences where sometimes hundreds of different researchers contribute to the publication (Kahn 2017). This underlying trend also contributes to the higher amount of funding that is shown by our analysis. 
Table 6 Top 10 most involved funding organizations for publications (published between 2009 and 2017) in which at least one author, whose primary or alternative address is located in South Africa, is contributing (Psychology)

\begin{tabular}{lll}
\hline Place & Funding organization & $\begin{array}{l}\text { Number of } \\
\text { funded publica- } \\
\text { tions }\end{array}$ \\
\hline 1 & National Institute of Mental Health & 52 \\
2 & National Research Foundation of South Africa & 51 \\
3 & National Institute on Drug Abuse & 36 \\
4 & Medical Research Council of South Africa & 29 \\
5 & Eunice Kennedy Shriver National Institute of Child Health and & 26 \\
6 & Human Development & 20 \\
7 & Wellcome Trust & 20 \\
8 & Fogarty International Center & 19 \\
9 & Netherlands Organisation for Scientific Research & 18 \\
10 & Medical Research Council of the United Kingdom & 16 \\
\hline
\end{tabular}

Based on the summation of funded publications across the different fields, we found that the three most frequently involved funding organizations are the National Research Foundation of South Africa (2333 funded publication), National Institute of Allergy and Infectious Diseases (698 funded publications), and the Wellcome Trust (535 funded publications) (see Table 6; see Tables 16, 17, 18, 19, 20, 21, 22, 23, 24 in "Appendix"). It is important to highlight these institutions since they contribute to a quantity of publications that is above the overall mean of the top 10 most involved institutions. However, it is important to clarify that the main authors, who are not always the selected authors with registered address in South Africa, define the direction and subfield of the publications. This also means that these authors are the ones responsible for the establishment of the funding relation. With this in mind, it is important to evaluate the emerging results in the light of the analysis we conducted on the number of co-publications in combination with the authorship positions that are taken by the selected authors.

\section{Discussion}

\section{Limitations}

The observed results should be taken cautiously due to some limitations of the analysis. First, it is important to clarify that in our analysis, collaboration is based on co-authorship, which may not accurately represent the many forms of collaboration that might occur (Kahn 2017). The nature and direction of collaboration are not indicated by listing only co-authorship, especially in the prior mentioned mega-science fields such as Astronomy or Particle Physics (Kahn 2017). Second, the WoS has the common shortcoming of other international databases of not including some of the scientific publications that are published in African journals (Cloete et al. 2015). Nevertheless, this quantity has decreased in the last decade (Cloete et al. 2015). Third, we used a 17 year publication window (from 2000 until 2017), which does not include the most up to date (published in 2018) publications, since, at the time of the analysis, the database did not have this information. Fourth, the selected fields for analysis were not a 
comprehensive account of African science. In future analyses, a higher diversity of fields can be included. Finally, the statistical tools, including the centrality measures and the Louvain modularity analysis, were chosen as these are widely applied in network analysis, but other tests and measurements can potentially be included in the future.

\section{Conclusion}

Based on the conducted analysis, we can conclude that, even though the South African research community has a major role in intercontinental scientific collaboration, this influence is mainly manifested in the fields of Zoology, Ecology, Water Resources, and Plant Sciences. Furthermore, we can also see that, when considering the quantity of co-publications, more technical fields are featured more prominently across the African continent, which has been prior supported by Cloete et al. (2015), as well.

In addition, the analysis measuring the position of authorship has shown that authors located in South Africa take first author positions the most frequently in Psychology compared to the rest of the fields. In addition, the combination of authorship analysis and collaboration maps has shown that there is dominance in the aforementioned fields (Zoology, Ecology, Water Resources, and Plant Sciences) but this influence has to be carefully interpreted in the light of the position the selected authors take. From the perspective of emergent social and/or economic issues, research institutions are naturally in the need to channel significant resources to scientific research involving regional problems related, specifically, to Africa (locally relevant diseases, maintenance of ecological and zoological resources). On the other hand, the main research institutes must widen their approach towards other fields and areas of socio-cultural relevance that potentially help increasing international cooperation, which in return heightens the level of scientific production and research skills. This means that research deemed valuable to the international research community is unlikely to be identical to locally relevant research, as researchers face a potential conflict between choosing to emphasize research that is locally or internationally relevant.

Moreover, it became visible, through the conducted Louvain Modularity analysis on collaborating communities that intercontinental collaboration is under major expansion. In addition, it was shown that Astronomy and Astrophysics, as well as Particle and field physics, take up the majority of primary positions in the investment agenda of the most influential funding organizations. Even though this highlights the current direction and preference of scientific funding and the demand of substantial input these two fields require, this pattern seems quite problematic due to the questionable local need to have these fields (astronomy/ astrophysics/particle and field physics) taking up funding priority and if they eve address priorities on the African continent. This is a clear indicator of the still present western influence on the agenda setting of African science through financial means. It is also necessary to see that the National Research Foundation (NRF) still provides the highest contribution to the selected fields, even though its planned funding cuts had a serious impact on the South African academic community (Wild 2017). As some authors have already highlighted it is very important for the future of African research to establish a balanced partnership with researchers and institutions located in Africa and ensure that the quantity and quality of involvement is equally discussed and agreed upon (Dodsworth and Cheeseman 2017).

Finally, the conducted analysis supports the fact that, even though South Africa has a dominant presence in the continental scientific collaboration process, further research is needed to rigorously investigate the presence and influence of other African countries regarding within- and intercontinental scientific collaboration. 
Acknowledgements This work is partially funded by the South African DST-NRF Centre of Excellence in Scientometrics and Science, Technology and Innovation Policy (SciSTIP).

\section{Compliance with ethical standards}

Conflict of interest The authors declare that they have no conflict of interest.

Open Access This article is distributed under the terms of the Creative Commons Attribution 4.0 International License (http://creativecommons.org/licenses/by/4.0/), which permits unrestricted use, distribution, and reproduction in any medium, provided you give appropriate credit to the original author(s) and the source, provide a link to the Creative Commons license, and indicate if changes were made.

\section{Appendix}

See Tables 7, 8, 9, 10, 11, 12, 13, 14, 15, 16, 17, 18, 19, 20, 21, 22, 23 and 24 and Figs. 2, $3,4,5,6,7,8,9$ and 10 .

Table 7 Psychology centrality measurements

\begin{tabular}{lllllll}
\hline Psychology & \multicolumn{7}{l}{ Cosition } & Betweenness & Countries & Closeness & Countries & Degree & Countries \\
\hline 1 & 0.0001688 & NG & 0.01264 & NG & 65 & NG \\
2 & 0.0001274 & UG & 0.00655 & ZA & 15 & UG \\
3 & 0.0000099 & ZA & 0.00419 & UG & 11 & GH \\
4 & 0.0000079 & GH & 0.00264 & ZA & 7 & ZA \\
5 & 0.0000057 & BO & 0.00239 & BO & 5 & ZA \\
6 & 0.0000013 & ZA & 0.00229 & GH & 3 & EG \\
7 & 0.0000001 & EG & 0.00206 & EG & 3 & MO \\
8 & 0.0000001 & EG & 0.00076 & EG & 2 & EG \\
9 & 0.0000001 & ZA & 0.00076 & MO & 2 & EG \\
10 & 0.0000000 & EG & 0.00057 & EG & 2 & ZA \\
\hline
\end{tabular}

Table 8 Zoology centrality measurements

\begin{tabular}{|c|c|c|c|c|c|c|}
\hline \multicolumn{7}{|l|}{ Zoology } \\
\hline Position & Betweenness & Countries & Closeness & Countries & Degree & Countries \\
\hline 1 & 0.003702 & $\mathrm{ZA}$ & 0.024185 & ZA & 30 & ZA \\
\hline 2 & 0.002521 & $\mathrm{ZA}$ & 0.021836 & $\mathrm{ZA}$ & 15 & ZA \\
\hline 3 & 0.001417 & $\mathrm{ZA}$ & 0.021002 & ZA & 15 & ZA \\
\hline 4 & 0.001373 & $\mathrm{ZA}$ & 0.020934 & $\mathrm{ZA}$ & 14 & ZA \\
\hline 5 & 0.000950 & $\mathrm{ZA}$ & 0.020157 & $\mathrm{ZA}$ & 13 & $\mathrm{ZA}$ \\
\hline 6 & 0.000929 & $\mathrm{ZA}$ & 0.018582 & ZA & 11 & ZA \\
\hline 7 & 0.000712 & $\mathrm{ZA}$ & 0.01838 & $\mathrm{ZA}$ & 9 & $\mathrm{ZA}$ \\
\hline 8 & 0.000416 & $\mathrm{ZA}$ & 0.017627 & $\mathrm{ZA}$ & 8 & ZA \\
\hline 9 & 0.000381 & $\mathrm{ZA}$ & 0.016589 & $\mathrm{ZA}$ & 8 & $\mathrm{ZA}$ \\
\hline 10 & 0.000180 & $\mathrm{ZA}$ & 0.015197 & ZA & 7 & ZA \\
\hline
\end{tabular}


Table 9 Water Resources centrality measurements

\begin{tabular}{lllllll}
\hline \multicolumn{2}{l}{ Water Resources } \\
\hline Position & Betweenness & Countries & Closeness & Countries & Degree & Countries \\
\hline 1 & 0.001180 & ZA & 0.012472 & ZA & 42 & ZA \\
2 & 0.000764 & ZA & 0.011887 & ZA & 17 & BT \\
3 & 0.000724 & ZA & 0.011253 & ZA & 16 & ZA \\
4 & 0.000563 & ZA & 0.011037 & BT & 15 & ZA \\
5 & 0.000486 & ZA & 0.010209 & ZA & 14 & ZA \\
6 & 0.000437 & BT & 0.010174 & ZA & 14 & ZA \\
7 & 0.000292 & EG & 0.010167 & ZA & 11 & ZA \\
8 & 0.000259 & ZA & 0.010153 & ZA & 10 & ZA \\
9 & 0.000216 & ZA & 0.010126 & ZA & 10 & ZA \\
10 & 0.000133 & ZA & 0.00975 & EG & 8 & ZA \\
\hline
\end{tabular}

Table 10 Tropical Medicine centrality measurements

\begin{tabular}{lllllll}
\hline \multicolumn{2}{l}{ Tropical Medicine } \\
\hline Position & Betweenness & Countries & Closeness & Countries & Degree & Countries \\
\hline 1 & 0.00490 & GH & 0.104461 & KY & 59 & SE \\
2 & 0.00260 & UG & 0.104061 & CA & 57 & GH \\
3 & 0.00160 & GH & 0.104016 & GH & 48 & NI \\
4 & 0.00135 & CA & 0.103862 & UG & 47 & UG \\
5 & 0.00134 & KY & 0.10217 & NG & 38 & CA \\
6 & 0.00111 & NG & 0.101229 & SE & 36 & KE \\
7 & 0.00080 & SE & 0.09956 & GH & 33 & GH \\
8 & 0.00070 & EG & 0.093777 & KY & 21 & EG \\
9 & 0.00043 & EG & 0.093143 & EG & 12 & EG \\
10 & 0.00027 & KY & 0.092993 & EG & 11 & KE \\
\hline
\end{tabular}

Table 11 Plant Sciences centrality measurements

\begin{tabular}{lllllll}
\hline \multicolumn{2}{l}{ Plant Sciences } \\
\hline Position & Betweenness & Countries & Closeness & Countries & Degree & Countries \\
\hline 1 & 0.00552 & ZA & 0.044517 & ZA & 59 & ZA \\
2 & 0.00295 & CA & 0.042412 & ZA & 51 & ZA \\
3 & 0.00263 & ZA & 0.042229 & ZA & 39 & CA \\
4 & 0.00232 & BT & 0.041943 & ZA & 29 & BT \\
5 & 0.00222 & ZA & 0.041712 & CA & 28 & ZA \\
6 & 0.00192 & ZA & 0.040784 & BT & 28 & ZA \\
7 & 0.00183 & ZA & 0.038955 & ZA & 22 & ZA \\
8 & 0.00128 & ZA & 0.038249 & ZA & 17 & EG \\
9 & 0.00112 & ZA & 0.038223 & ZA & 16 & ZA \\
10 & 0.00079 & EG & 0.038127 & ZA & 15 & ZA \\
\hline
\end{tabular}


Table 12 Parasitology centrality measurements

\begin{tabular}{lllllll}
\hline Parasitology & \multicolumn{7}{l}{} \\
\hline Position & Betweenness & Countries & Closeness & Countries & Degree & Countries \\
\hline 1 & 0.00340 & NG & 0.055995 & NG & 38 & TU \\
2 & 0.00251 & ZA & 0.055888 & TU & 35 & GH \\
3 & 0.00170 & ZA & 0.055816 & GH & 34 & CA \\
4 & 0.00166 & ZA & 0.055816 & ZA & 33 & NG \\
5 & 0.00137 & ZA & 0.054776 & NG & 32 & ZA \\
6 & 0.00137 & GH & 0.052468 & EG & 26 & ZA \\
7 & 0.00104 & EG & 0.05246 & ZA & 21 & EG \\
8 & 0.00096 & UG & 0.052116 & ZA & 20 & ZA \\
9 & 0.00092 & CA & 0.051861 & ZA & 19 & SE \\
10 & 0.00066 & ZA & 0.051854 & EG & 16 & ZA \\
\hline
\end{tabular}

Table 13 Infectious Diseases centrality measurements

\begin{tabular}{lllllll}
\hline \multicolumn{2}{l}{ Infectious Diseases } \\
\hline Position & Betweenness & Countries & Closeness & Countries & Degree & Countries \\
\hline 1 & 0.016567014 & ZA & 0.15964 & ZA & 251 & ZA \\
2 & 0.0121137 & ZA & 0.154505 & ZA & 197 & ZA \\
3 & 0.008108202 & EGY & 0.14693 & UG & 133 & EG \\
4 & 0.006802919 & ZA & 0.145787 & EG & 115 & UG \\
5 & 0.006183579 & UG & 0.144279 & KE & 96 & KE \\
6 & 0.00518807 & KE & 0.139285 & KE & 96 & EG \\
7 & 0.004743269 & GH & 0.137199 & ZA & 95 & NG \\
8 & 0.004638794 & NG & 0.135584 & ZA & 85 & ZA \\
9 & 0.004441414 & CA & 0.134736 & SE & 65 & GH \\
10 & 0.004020661 & EGY & 0.133085 & GH & 63 & KE \\
\hline
\end{tabular}

Table 14 Immunology centrality measurements

\begin{tabular}{lllllll}
\hline Immunology & \multicolumn{7}{l}{ Cosition } & Betweenness & Countries & Closeness & Countries & Degree & Countries \\
\hline 1 & 0.00660 & ZA & 0.111182 & ZA & 129 & ZA \\
2 & 0.00453 & ZA & 0.106527 & ZA & 90 & ZA \\
3 & 0.00243 & UG & 0.104538 & UG & 65 & KE \\
4 & 0.00168 & ZA & 0.10094 & KE & 62 & UG \\
5 & 0.00152 & AL & 0.093199 & ZA & 51 & GH \\
6 & 0.00141 & KE & 0.091437 & ZA & 39 & ZA \\
7 & 0.00140 & GH & 0.09096 & ZA & 24 & SE \\
8 & 0.00128 & GH & 0.087059 & SE & 23 & ZA \\
9 & 0.00128 & SE & 0.086416 & ZA & 21 & ZA \\
10 & 0.00097 & EG & 0.084595 & GH & 21 & ZA \\
\hline
\end{tabular}


Table 15 Ecology centrality measurements

\begin{tabular}{lllllll}
\hline Ecology & \multicolumn{7}{l}{} & & & \\
\hline Position & Betweenness & Countries & Closeness & Countries & Degree & Countries \\
\hline 1 & 0.00566 & ZA & 0.052531 & ZA & 73 & ZA \\
2 & 0.00302 & ZA & 0.052158 & ZA & 37 & ZA \\
3 & 0.00282 & ZA & 0.048707 & ZA & 35 & ZA \\
4 & 0.00267 & ZA & 0.048258 & ZA & 28 & ZA \\
5 & 0.00179 & ZA & 0.046413 & ZA & 26 & ZA \\
6 & 0.00167 & ZA & 0.045898 & ZA & 24 & CA \\
7 & 0.00160 & ZA & 0.045124 & ZA & 19 & ZA \\
8 & 0.00114 & ZA & 0.044645 & ZA & 18 & ZA \\
9 & 0.00089 & ZA & 0.044301 & ZA & 17 & ZA \\
10 & 0.00044 & ZA & 0.042633 & CA & 12 & ZA \\
\hline
\end{tabular}

Table 16 Top 10 most involved funding organizations for publications (published between 2009 and 2017) in which at least one author, whose primary or alternative address is located in South Africa, is contributing (Agricultural and Food Sciences)

\begin{tabular}{llc}
\hline Place & Funding organization & $\begin{array}{l}\text { Number of funded } \\
\text { publications }\end{array}$ \\
\hline 1 & National Research Foundation of South Africa & 487 \\
2 & Research Chairs Initiative & 94 \\
3 & Medical Research Council of South Africa & 72 \\
4 & University of Pretoria & 68 \\
5 & University of KwaZulu-Natal & 63 \\
6 & University of the Witwatersrand & 43 \\
7 & Natural Sciences and Engineering Research Council of Canada & 38 \\
8 & Wellcome Trust & 32 \\
9 & University of Cape Town & 31 \\
10 & Stellenbosch University & 30 \\
\hline
\end{tabular}

Table 17 Top 10 most involved funding organizations for publications (published between 2009 and 2017) in which at least one author, whose primary or alternative address is located in South Africa, is contributing (Zoology)

\begin{tabular}{llr}
\hline Place & Funding organization & $\begin{array}{l}\text { Number of funded } \\
\text { publications }\end{array}$ \\
\hline 1 & National Research Foundation of South Africa & 325 \\
2 & University of Pretoria & 85 \\
3 & University of the Witwatersrand & 50 \\
4 & University of KwaZulu-Natal & 48 \\
5 & Rhodes University & 26 \\
6 & Claude Leon Foundation & 26 \\
7 & NSF Division of Environmental Biology & 25 \\
8 & University of Cape Town & 24 \\
9 & Natural Sciences and Engineering Research Council of Canada & 21 \\
10 & Swiss National Science Foundation & 18 \\
\hline
\end{tabular}


Table 18 Top 10 most involved funding organizations for publications (published between 2009 and 2017) in which at least one author, whose primary or alternative address is located in South Africa, is contributing (Water Resources)

\begin{tabular}{lll}
\hline Place & Funding organization & $\begin{array}{l}\text { Number of funded } \\
\text { publications }\end{array}$ \\
\hline 1 & National Research Foundation of South Africa & 97 \\
2 & University of Johannesburg & 38 \\
3 & Tshwane University of Technology & 17 \\
4 & University of KwaZulu-Natal & 14 \\
5 & University of Cape Town & 14 \\
6 & University of the Witwatersrand & 10 \\
7 & German Academic Exchange Service & 10 \\
8 & University of Pretoria & 9 \\
9 & Dutch Government & 8 \\
10 & UNESCO & 7
\end{tabular}

Table 19 Top 10 most involved funding organizations for publications (published between 2009 and 2017) in which at least one author, whose primary or alternative address is located in South Africa, is contributing (Plant Sciences)

\begin{tabular}{lll}
\hline Place & Funding organization & Number of funded publications \\
\hline 1 & National Research Foundation of South Africa & 461 \\
2 & University of KwaZulu-Natal & 183 \\
3 & University of Johannesburg & 94 \\
4 & University of Pretoria & 83 \\
5 & Claude Leon Foundation & 64 \\
6 & University of Cape Town & 48 \\
7 & Tshwane University of Technology & 35 \\
8 & Ministry of Education, Youth and Sport & 34 \\
9 & National Geographic Society & 33 \\
10 & University of the Witwatersrand & 30 \\
\hline
\end{tabular}

Table 20 Top 10 most involved funding organizations for publications (published between 2009 and 2017) in which at least one author, whose primary or alternative address is located in South Africa, is contributing (Parasitology)

\begin{tabular}{lll}
\hline Place & Funding organization & Number of funded publications \\
\hline 1 & National Research Foundation of South Africa & 65 \\
2 & Wellcome Trust & 39 \\
3 & University of Pretoria & 34 \\
4 & National Institute of Allergy and Infectious Diseases & 26 \\
5 & Bill and Melinda Gates Foundation & 21 \\
6 & Biotechnology and Biological Sciences Research Council & 13 \\
7 & Research Foundation Flanders & 8 \\
8 & Medical Research Council of the United Kingdom & 8 \\
9 & Medical Research Council of South Africa & 8 \\
10 & Deutsche Forschungsgemeinschaft & 8 \\
\hline
\end{tabular}


Table 21 Top 10 most involved funding organizations for publications (published between 2009 and 2017) in which at least one author, whose primary or alternative address is located in South Africa, is contributing (Immunology)

\begin{tabular}{lll}
\hline Place & Funding organization & Number of funded publications \\
\hline 1 & National Institute of Allergy and Infectious Diseases & 81 \\
2 & Wellcome Trust & 76 \\
3 & Medical Research Council of South Africa & 50 \\
4 & National Research Foundation of South Africa & 48 \\
5 & Bill and Melinda Gates Foundation & 46 \\
6 & Research Chairs Initiative & 23 \\
7 & Medical Research Council of the United Kingdom & 23 \\
8 & World Health Organization & 16 \\
9 & United States Agency for International Development & 16 \\
10 & University of Cape Town & 15 \\
\hline
\end{tabular}

Table 22 Top 10 most involved funding organizations for publications (published between 2009 and 2017) in which at least one author, whose primary or alternative address is located in South Africa, is contributing (Ecology)

\begin{tabular}{lll}
\hline Place & Funding organization & Number of funded publications \\
\hline 1 & National Research Foundation of South Africa & 591 \\
2 & University of Cape Town & 102 \\
3 & University of Pretoria & 84 \\
4 & Stellenbosch University & 66 \\
5 & Andrew W. Mellon Foundation & 64 \\
6 & Research Chairs Initiative & 62 \\
7 & University of KwaZulu-Natal & 59 \\
8 & Natural Environment Research Council & 54 \\
9 & Australian Research Council & 52 \\
10 & Deutsche Forschungsgemeinschaft & 46 \\
\hline
\end{tabular}

Table 23 Top 10 most involved funding organizations for publications (published between 2009 and 2017) in which at least one author, whose primary or alternative address is located in South Africa, is contributing (Tropical Medicine)

\begin{tabular}{lll}
\hline Place & Funding organization & Number of funded publications \\
\hline 1 & Wellcome Trust & 44 \\
2 & National Research Foundation of South Africa & 34 \\
3 & World Health Organization & 25 \\
4 & United States Agency for International Development & 22 \\
5 & National Institute of Allergy and Infectious Diseases & 21 \\
6 & Bill \& Melinda Gates Foundation & 20 \\
7 & Medical Research Council of South Africa & 19 \\
8 & Fogarty International Center & 17 \\
9 & National Institutes of Health & 13 \\
10 & Medical Research Council of the United Kingdom & 11 \\
\hline
\end{tabular}


Table 24 Top 10 most involved funding organizations for publications (published between 2009 and 2017) in which at least one author, whose primary or alternative address is located in South Africa, is contributing (Infectious Diseases)

\begin{tabular}{lll}
\hline Place & Funding organization & $\begin{array}{l}\text { Number of funded } \\
\text { publications }\end{array}$ \\
\hline 1 & National Institute of Allergy and Infectious Diseases & 570 \\
2 & Wellcome Trust & 324 \\
3 & Bill \& Melinda Gates Foundation & 222 \\
4 & United States Agency for International Development & 219 \\
5 & Fogarty International Center & 179 \\
6 & National Research Foundation of South Africa & 174 \\
7 & Eunice Kennedy Shriver National Institute of Child Health and Human Development & 167 \\
8 & Medical Research Council of South Africa & 151 \\
9 & National Institutes of Health & 143 \\
10 & Centers for Disease Control and Prevention & 115 \\
\hline
\end{tabular}

(A)

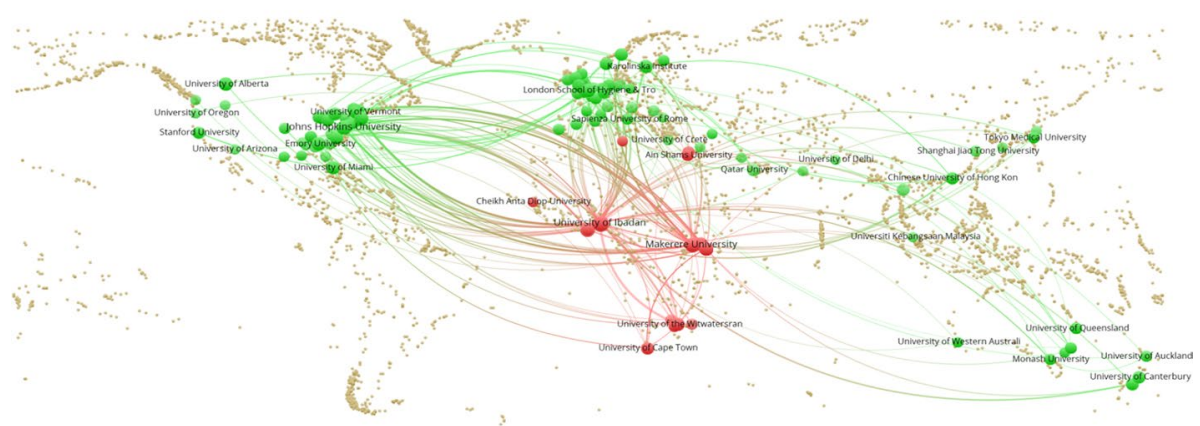

(B)

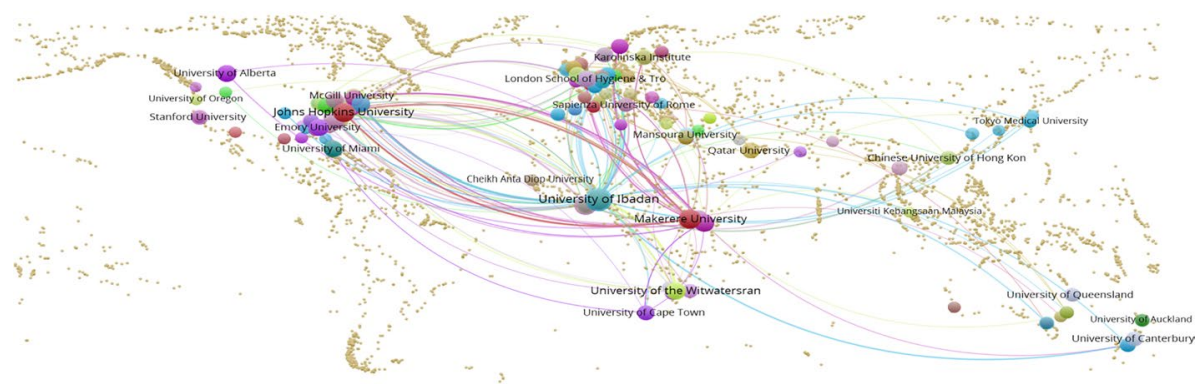

Fig. 2 a Collaboration between African and non-African research institutes in the field of Psychology. Red nodes represent African institutions and green the non-African ones. b Collaboration split to communities between African and non-African research institutes in the field of Psychology (Louvain Modularity). Each colour represents different communities based on the density of edges (representing collaboration) connecting the institutions. (Color figure online) 
(A)

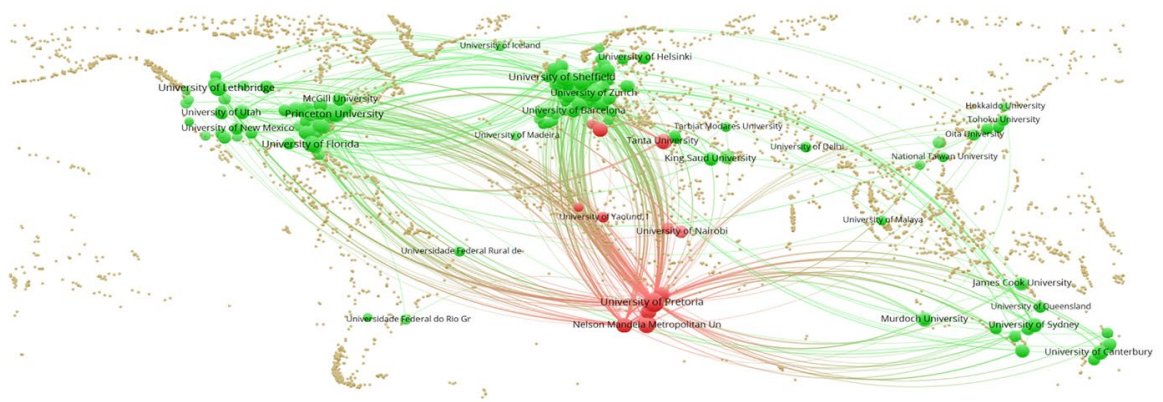

8 vosviewer

(B)

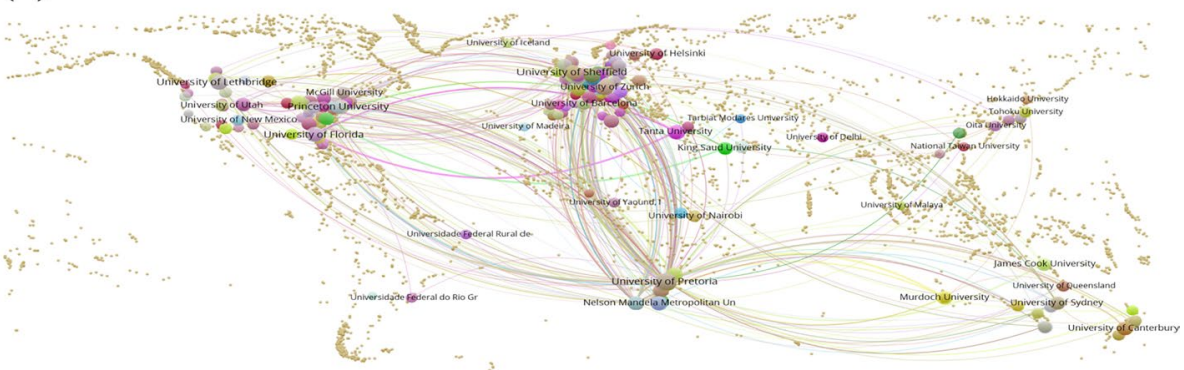

A vosviewer

Fig. 3 a Collaboration between African and non-African research institutes in the field of Zoology. Red nodes represent African institutions and green the non-African ones. b Collaboration split to communities between African and non-African research institutes in the field of Zoology (Louvain Modularity). Each colour represents different communities based on the density of edges (representing collaboration) connecting the institutions. (Color figure online) 
(A)

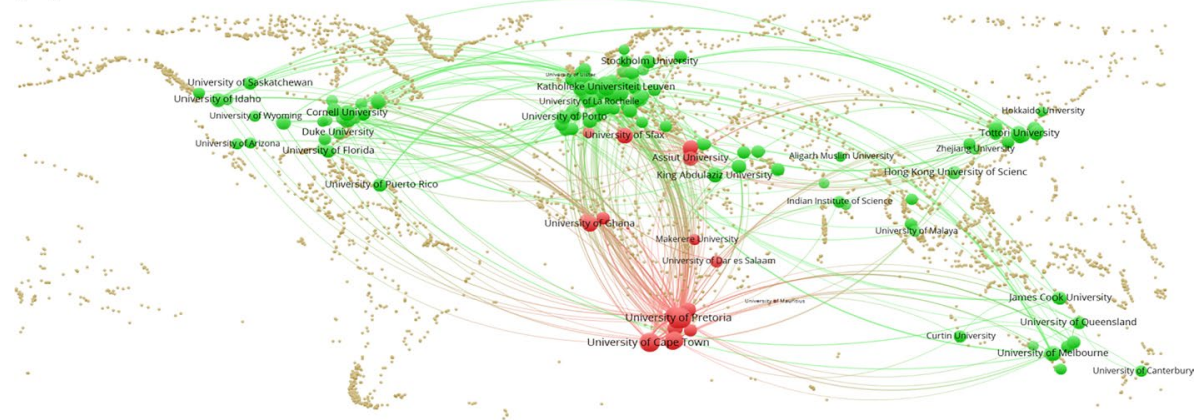

B vosviewer

(B)

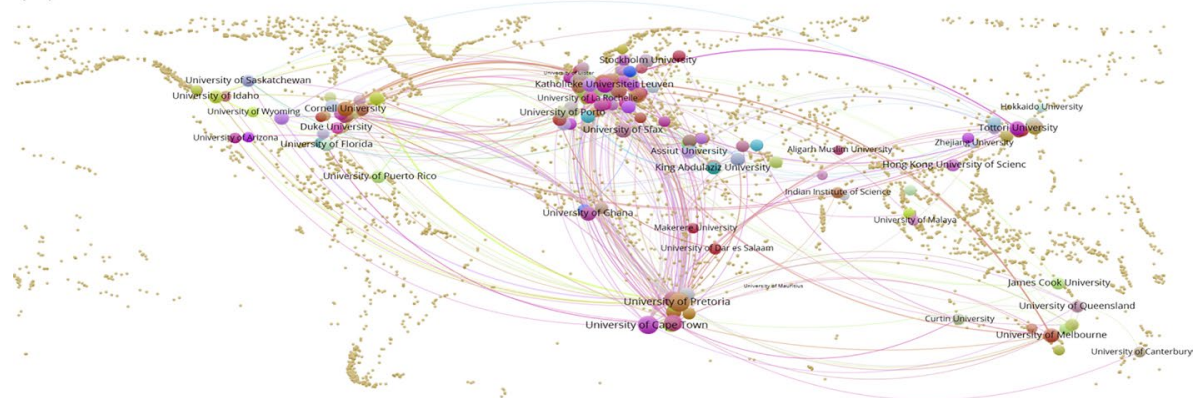

A vosviewer

Fig. 4 a Collaboration between African and non-African research institutes in the field of Water Resources. Red nodes represent African institutions and green the non-African ones. b Collaboration split to communities between African and non-African research institutes in the field of Water Resources (Louvain Modularity). Each colour represents different communities based on the density of edges (representing collaboration) connecting the institutions. (Color figure online) 
(A)

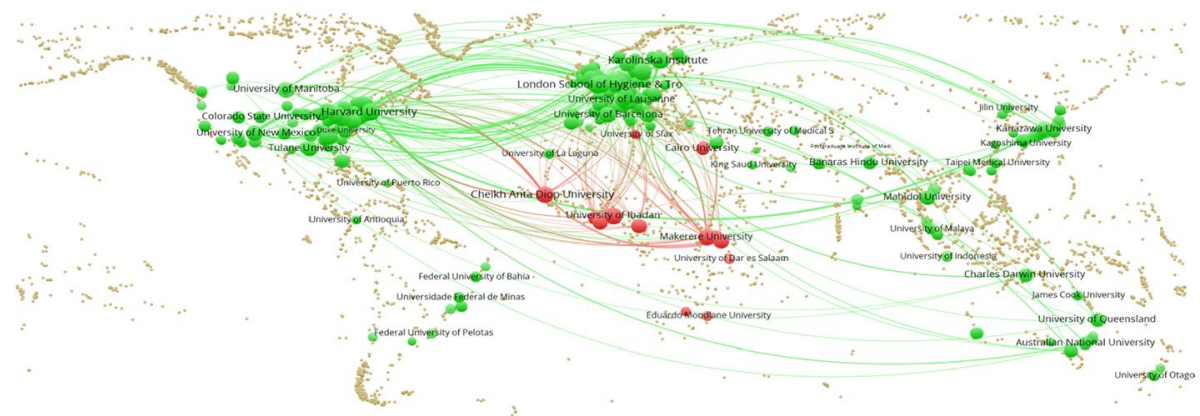

An vosviewer

(B)

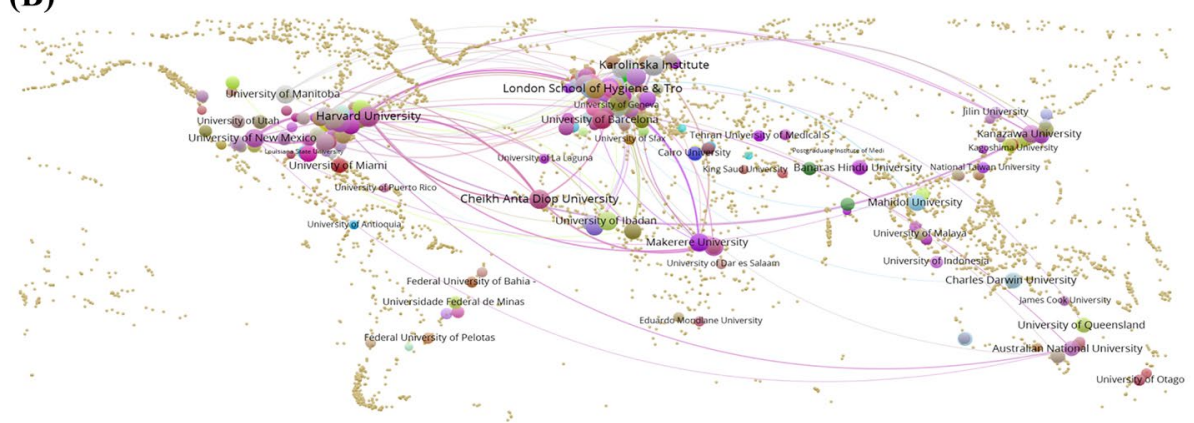

\& vosviewer

Fig. 5 a Collaboration between African and non-African research institutes in the field of Tropical Medicine. Red nodes represent African institutions and green the non-African ones. b Collaboration split to communities between African and non-African research institutes in the field of Tropical Medicine (Louvain Modularity). Each colour represents different communities based on the density of edges (representing collaboration) connecting the institutions. (Color figure online) 
(A)

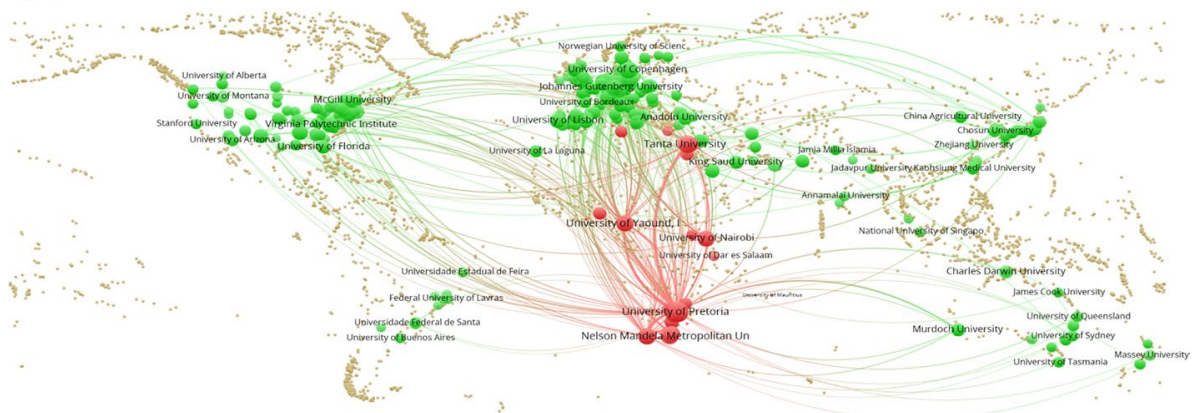

A vosviewer

(B)

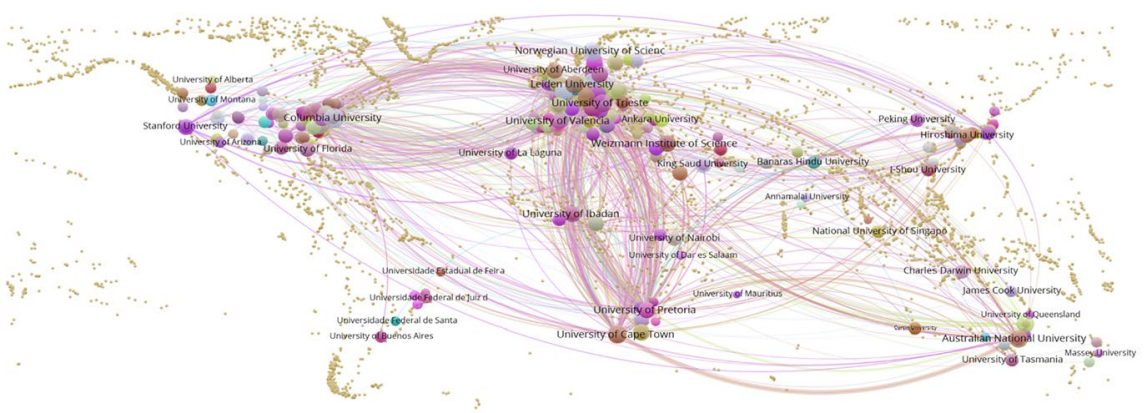

8 vosviewer

Fig. 6 a Collaboration between African and non-African research institutes in the field of Plant Sciences. Red nodes represent African institutions and green the non-African ones. b Collaboration split to communities between African and non-African research institutes in the field of Plant Sciences (Louvain Modularity). Each colour represents different communities based on the density of edges (representing collaboration) connecting the institutions. (Color figure online) 
(A)

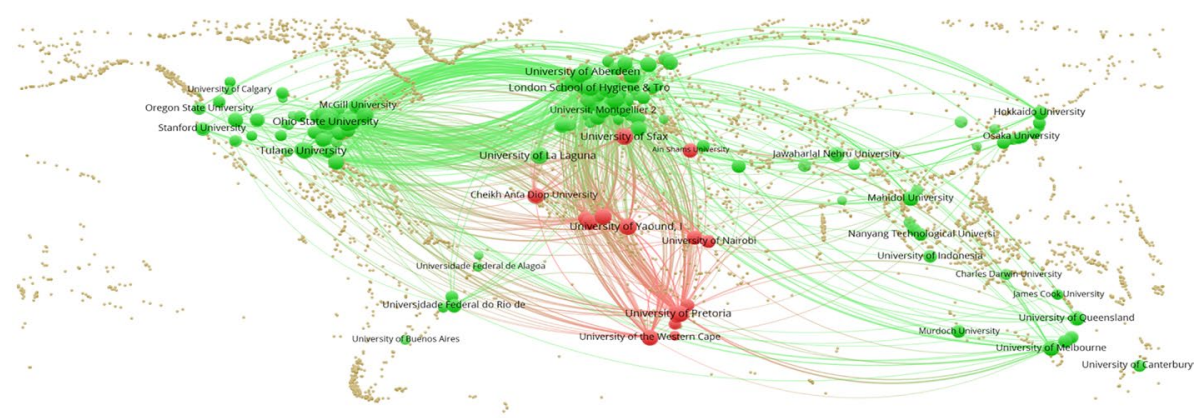

As vosviewer

(B)

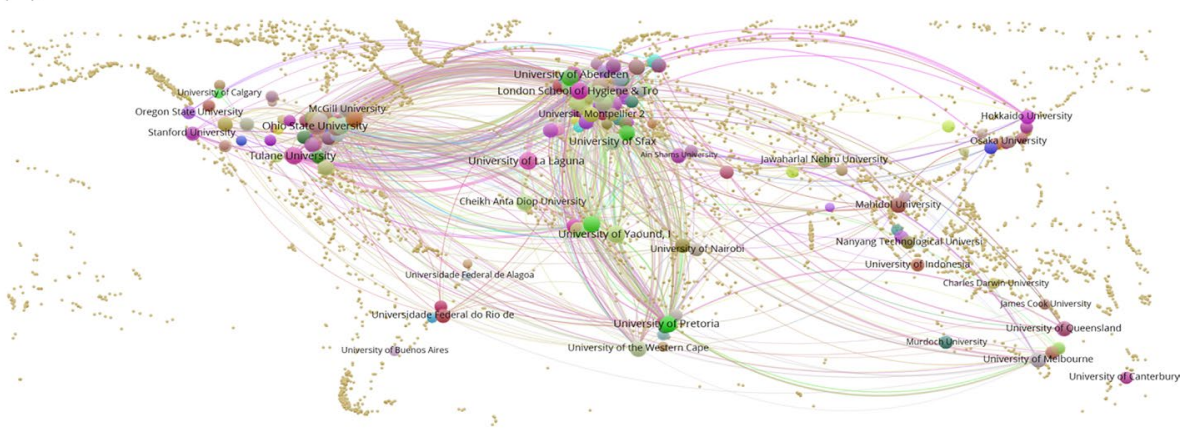

8 vosviewer

Fig. 7 a Collaboration between African and non-African research institutes in the field of Parasitology. Red nodes represent African institutions and green the non-African ones. b Collaboration split to communities between African and non-African research institutes in the field of Parasitology (Louvain Modularity). Each colour represents different communities based on the density of edges (representing collaboration) connecting the institutions. (Color figure online) 
(A)

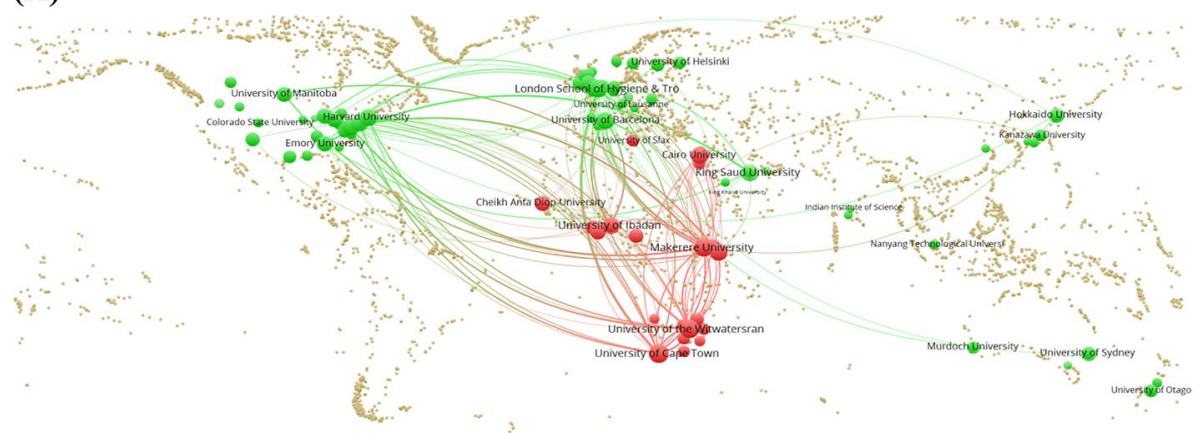

Anosviewer

(B)

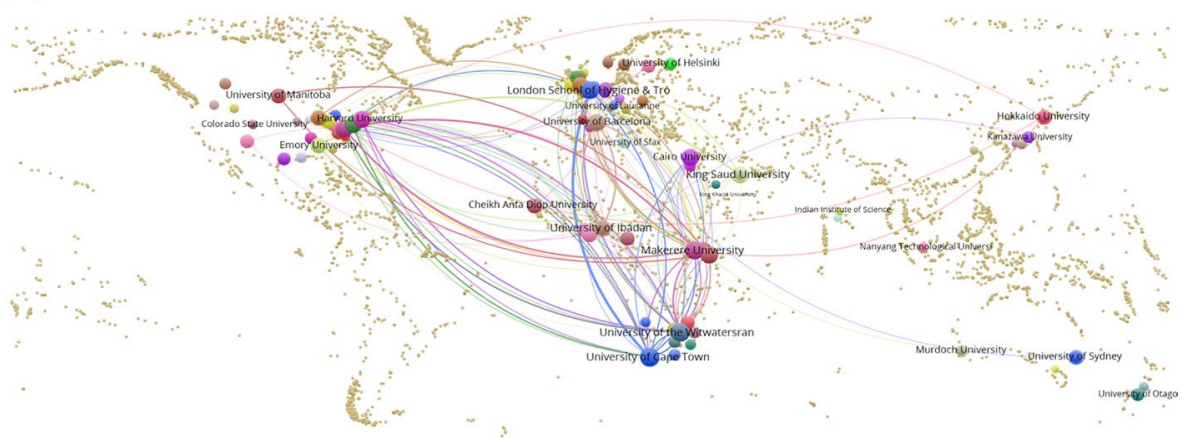

Fig. 8 a Collaboration between African and non-African research institutes in the field of Infectious Diseases. Red nodes represent African institutions and green the non-African ones. b Collaboration split to communities between African and non-African research institutes in the field of Infectious Disease (Louvain Modularity). Each colour represents different communities based on the density of edges (representing collaboration) connecting the institutions. (Color figure online) 
(A)

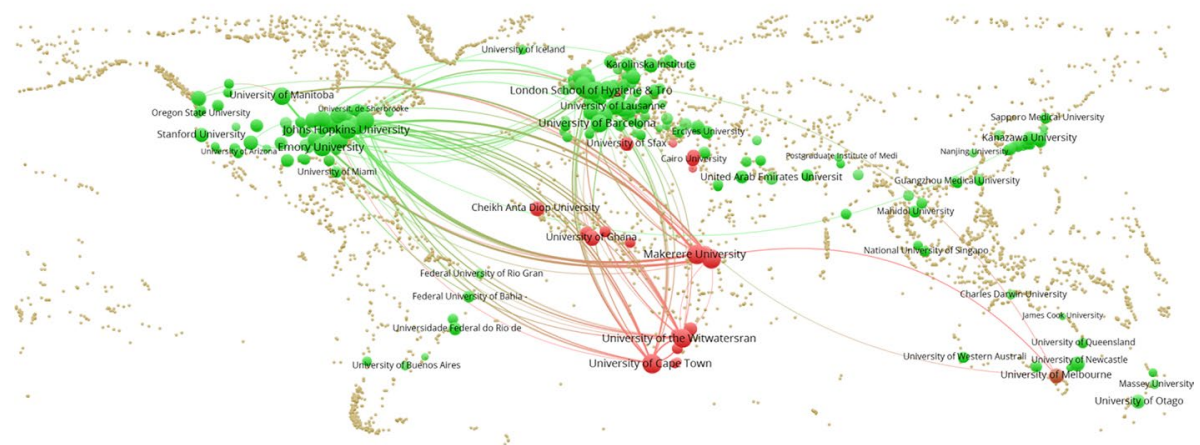

A vosviewer

(B)

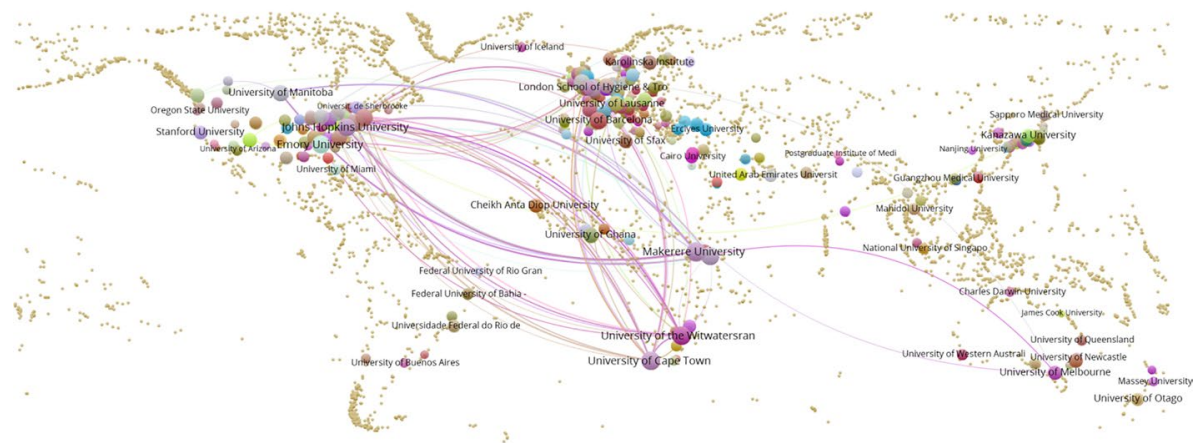

is vosviewer

Fig. 9 a Collaboration between African and non-African research institutes in the field of Immunology. Red nodes represent African institutions and green the non-African ones. b Collaboration split to communities between African and non-African research institutes in the field of Immunology (Louvain Modularity). Each colour represents different communities based on the density of edges (representing collaboration) connecting the institutions. (Color figure online) 


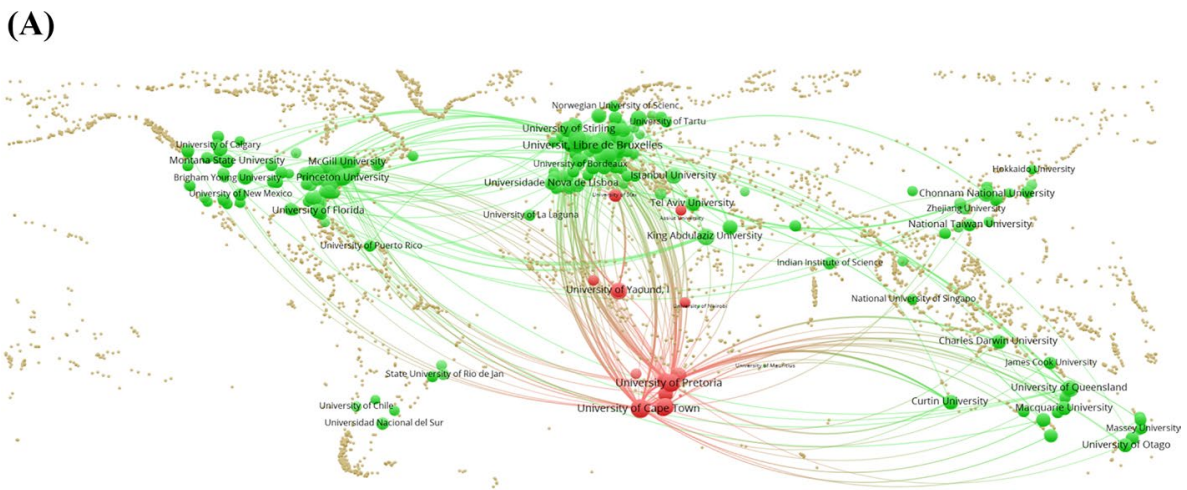

sosviewer

(B)

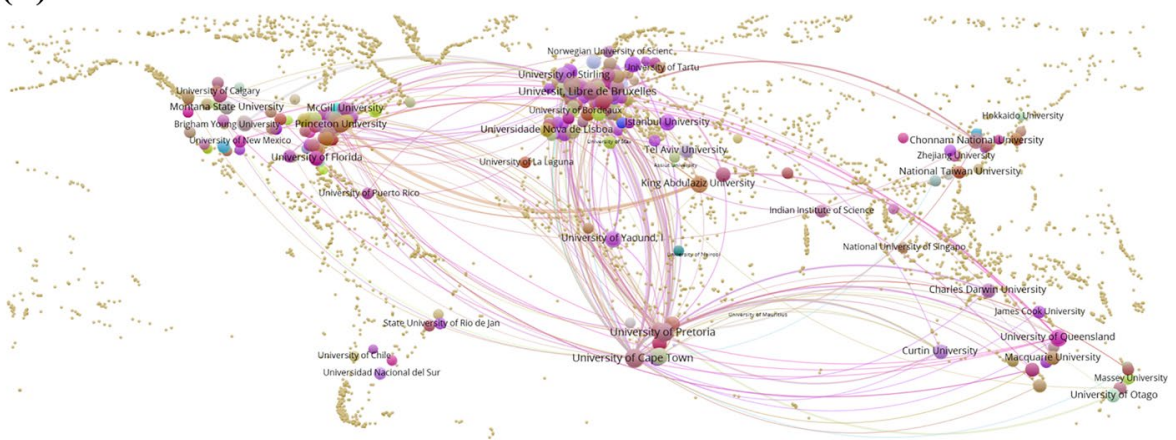

As vosviewer

Fig. 10 a Collaboration between African and non-African research institutes in the field of Ecology. Red nodes represent African institutions and green the non-African ones. b Collaboration split to communities between African and non-African research institutes in the field of Ecology (Louvain Modularity). Each colour represents different communities based on the density of edges (representing collaboration) connecting the institutions. (Color figure online)

\section{References}

AOSTI. (2014). Assessment of scientific production in the African union 2005-2010. Malabo: The African Observatory of Science, Technology and Innovation (AOSTI).

Batagelj, V., \& Mrvar, V. (2003). Pajek-Analysis and visualization of large networks. In M. Jünger \& P. Mutzel (Eds.), Graph drawing software (pp. 77-103). Berlin: Springer.

Beaudry, C., \& Mouton, J. (2017). Young scientists in Africa: Factors influencing research performance and career development (Mid-term report). Centre for Research on Evaluation, Science and Technology. South Africa: Stellenbosch University.

Bhattacharya, S. (2010). Authorship issue explained. Indian Journal of Plastic Surgery, 43(2), 233. https:// doi.org/10.4103/0970-0358.73482.

Blondel, V. D., Guillaume, J., Lambiotte, R., \& Lefebvre, E. (2008). Fast unfolding of communities in large networks. Journal of Statistical Mechanics: Theory and Experiment. https://doi.org/10.1088/1742$5468 / 2008 / 10 / \mathrm{p} 10008$.

Briggs, R. C., \& Weathers, S. (2016). Gender and location in African politics scholarship: The other white man's burden? African Affairs, 115(460), 466-489. https://doi.org/10.1093/afrat/adw009. 
Cloete, N., Maassen, P. A., \& Bailey, T. (2015). Knowledge production and contradictory functions in African higher education. Cape Town: African Minds.

Dodsworth, S., \& Cheeseman, N. (2017). The potential and pitfalls of collaborating with development organizations and policy makers in Africa. African Affairs, 117(466), 130-145. https://doi.org/10.1093/ afraf/adx041.

Evans, T. S., Lambiotte, R., \& Panzarasa, P. (2011). Community structure and patterns of scientific collaboration in business and management. Scientometrics, 89(1), 381-396. https://doi.org/10.1007/s1119 2-011-0439-1.

Gibney, E. (2016). Europe plans giant billion-euro quantum technologies project. Nature, 532(7600), 426. https://doi.org/10.1038/nature.2016.19796.

Hicks, D., Wouters, P., Waltman, L., Rijcke, S. D., \& Rafols, I. (2015). Bibliometrics: The Leiden Manifesto for research metrics. Nature, 520(7548), 429-431. https://doi.org/10.1038/520429a.

Kahn, M. (2017). Co-authorship as a proxy for collaboration: A cautionary tale. Science and Public Policy, 45(1), 117-123. https://doi.org/10.1093/scipol/scx052.

Klein, J. T. (2008). Evaluation of interdisciplinary and transdisciplinary research. American Journal of Preventive Medicine. https://doi.org/10.1016/j.amepre.2008.05.010.

Mâsse, L. C., Moser, R. P., Stokols, D., Taylor, B. K., Marcus, S. E., Morgan, G. D., et al. (2008). Measuring collaboration and transdisciplinary integration in team science. American Journal of Preventive Medicine. https://doi.org/10.1016/j.amepre.2008.05.020.

Nhemachena, A., Mlambo, N., \& Kaundjua, M. (2016). The notion of the 'field' and the practices of researching and writing Africa: Towards decolonial praxis. Journal of Pan African Studies, 9(7), $15-37$.

NSB. (2016). Science and engineering indicators 2016. Washington, DC: National Science Board.

O'Brien, J. (2017). The future is quantum: Solution to the world's critical problems. Retrieved from https:// www.ft.com/content/6711e5c2-0e83-11e7-b030-768954394623.

OECD. (2016). OECD science, technology and innovation outlook 2016. Paris: OECD Publishing. https:// doi.org/10.1787/sti_in_outlook-2016-en.

Preskill, J. (2018). Quantum computing in the NISQ era and beyond. Based on a keynote address at quantum computing for business, December 5, 2017.

Ranjbar-Sahraei, B., \& Negenborn, R. R. (2017). Research positioning and trend identification-A dataanalytics toolbox [booklet]. Delft: TU Delft.

Roper, L. (2002). Achieving successful academic-practitioner research collaborations. Development in Practice, 12(3-4), 338-345. https://doi.org/10.1080/0961450220149717.

Ruiz-Castillo, J., \& Costas, R. (2014). The skewness of scientific productivity. Journal of Informetrics, 8(4), 917-934. https://doi.org/10.1016/j.joi.2014.09.006.

Sonnenwald, D. H. (2007). Scientific collaboration. In B. Cronin (Ed.), Annual review of information science and technology (Vol. 41, pp. 643-681). Medford, NJ: Information Today.

Sooryamoorthy, R. (2013a). Publication productivity and collaboration of researchers in South Africa: New empirical evidence. Scientometrics, 98(1), 531-545. https://doi.org/10.1007/s11192-013-0990-z.

Sooryamoorthy, R. (2013b). Scientific collaboration in South Africa. South African Journal of Science, 109(5/6), 1-5. https://doi.org/10.1590/sajs.2013/a0016.

Sooryamoorthy, R., \& Shrum, W. (2007). Does the internet promote collaboration and productivity? Evidence from the scientific community in South Africa. Journal of Computer-Mediated Communication, 12(2), 733-751. https://doi.org/10.1111/j.1083-6101.2007.00347.x.

UNESCO. (2010). World science report 2010. Paris: UNESCO.

Van Eck, N. J., \& Waltman, L. (2010). Software survey: VOSviewer, a computer program for bibliometric mapping. Scientometrics, 84(2), 523-538.

Wasserman, S., \& Faust, K. (2016). Social network analysis: Methods and applications. New York, NY: Cambridge University Press.

Whitelock, P., \& Oluseyi, H. M. (2008). Astrophysics in Southern Africa. In AIP conference proceedings. https://doi.org/10.1063/1.2905138.

Wild, S. (2017). South African Researchers Bemoan Slashed Funds. Nature. https://doi.org/10.1038/natur e.2017.22816. Retrieved from https://www.nature.com/news/south-african-researchers-bemoan-slash ed-funds-1.22816.

Yegros-Yegros, A., Rafols, I., \& D’Este, P. (2015). Does interdisciplinary research lead to higher citation impact? The different effect of proximal and distal interdisciplinarity. PLOS ONE. https://doi. org/10.1371/journal.pone.0135095. 